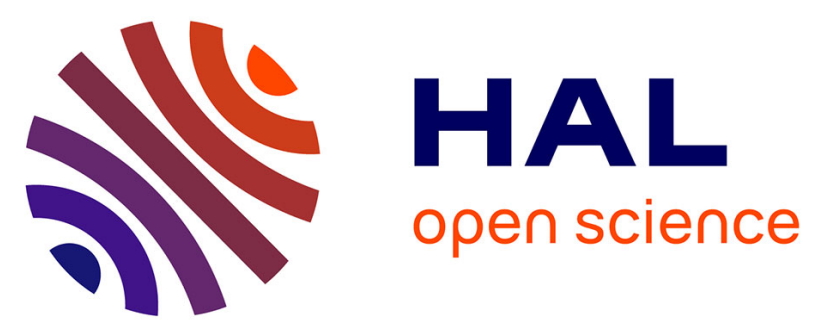

\title{
Electric Current as a Driving Force for Interphase Growth in Spark Plasma Sintered Dielectric Composites
} Marjorie Albino, U-Chan Chung, Ahmad Kassas, Julien Lesseur, Dominique Bernard, Catherine Elissalde, Mario Maglione

\section{- To cite this version:}

Marjorie Albino, U-Chan Chung, Ahmad Kassas, Julien Lesseur, Dominique Bernard, et al.. Electric Current as a Driving Force for Interphase Growth in Spark Plasma Sintered Dielectric Composites. Journal of the American Ceramic Society, 2016, 99 (2), pp.406-409. 10.1111/jace.14052 . hal-01278740

\author{
HAL Id: hal-01278740 \\ https://hal.science/hal-01278740
}

Submitted on 15 Jan 2021

HAL is a multi-disciplinary open access archive for the deposit and dissemination of scientific research documents, whether they are published or not. The documents may come from teaching and research institutions in France or abroad, or from public or private research centers.
L'archive ouverte pluridisciplinaire HAL, est destinée au dépôt et à la diffusion de documents scientifiques de niveau recherche, publiés ou non, émanant des établissements d'enseignement et de recherche français ou étrangers, des laboratoires publics ou privés. 


\title{
Electric Current as a Driving Force for Interphase Growth in Spark Plasma Sintered Dielectric Composites
}

\author{
Marjorie Albino, ${ }^{\dagger}$ U-Chan Chung, Ahmad Kassas, Julien Lesseur, Dominique Bernard, \\ Catherine Elissalde, and Mario Maglione \\ CNRS, Univ. Bordeaux, ICMCB, UPR 9048, Pessac F 33600, France
}

\begin{abstract}
All-oxide composites are increasingly investigated in the field of microelectronics and telecommunications because of their multifunctionalities. Advanced control of interfaces is required to fully tune the macroscopic properties of the composites. Processing ferroelectric $\mathrm{Ba}_{0.65} \mathrm{Sr}_{0.35} \mathrm{TiO}_{3}$ (BST65/35)- $\mathrm{TiO}_{2}$ composites by Spark Plasma Sintering (SPS), we show that the SPS electric current promotes an interphase growth whose thickness depends on the $\mathrm{BST} / \mathrm{TiO}_{2}$ stacking and on the current direction. In all cases, the interface is composed of $\mathrm{Ba}_{1.14(2)}$ $\mathrm{Ti}_{8} \mathrm{O}_{16-\delta}$ a highly defective, but stable phase which can be used to tune the overall dielectric properties of the composites.
\end{abstract}

\section{Introduction}

$\mathrm{D}$ IELECTRIC properties can be tuned in ferroelectric based composites controlling charged defects at interfaces. Focusing on $\mathrm{BaTiO}_{3}$ ceramics, giant effective dielectric parameters can be obtained by appropriate substitutions, by assembling different phases, or decreasing grain size using fast sintering such as SPS. ${ }^{1-3}$ The charges, at the origin of huge permittivity values, can arise from the reduced state of titanium due to high density of oxygen vacancies. Recently, colossal permittivity was also reported in $(\mathrm{Nb}+\mathrm{In})$ co doped $\mathrm{TiO}_{2}$ ceramics and defects engineering at the grain bound aries was explored using the specific features of SPS to reach in depth understanding of the resulting dielectric properties. ${ }^{4}$ In all cases, giant effective dielectric properties are related to the localization of free electronic charges at interfaces what ever their 3D extension and their density in the materials. However, in composites, both a control and a detailed inves tigation of the chemistry and structure at the interface are required to tune dielectric properties. SPS is widely used for the assembly of composites, but the current and/or tempera ture effects on the rate of growth of interphases was mainly studied for multilayers intermetallic systems. ${ }^{5-7}$ The electric current is mostly assumed to enhance sintering by activating mass transport mechanisms, but its influence on the charge defects concentration and mobility was demonstrated. The impact of both the current density and direction on the for mation of interphases was recently reported. ${ }^{8}$ It was shown that the current direction did not influence the direction of the atomic diffusion in most intermetallics. ${ }^{9-11}$

We show here that such studies can be extended to dielec tric materials by adjusting the composite architecture (bilayer, multilayer or random 3D mixing) and the SPS conditions. We used SPS on ceramic composites made of ferroelectric $\mathrm{Ba}_{0.65} \mathrm{Sr}_{0.35} \mathrm{TiO}_{3}$ (BST65/35) and dielectric $\mathrm{TiO}_{2}$ phases to probe the reactivity at the interfaces. Our main result is that the electrical current direction can tune the interphase growth. We ascribe this to the preferential titanium reduction in $\mathrm{TiO}_{2}$. As a consequence, we observe strong variations in the dielec tric properties depending on the composite architecture and on the direction of the current during SPS. The specific SPS conditions thus enable the control of both the interface between the two components and the reduction level leading to interface driven dielectric properties.

\section{Experimental Procedure}

Bilayers and multilayer stacks were prepared using BST65/35 powders, synthesized by solid state reaction, and commercial $\mathrm{TiO}_{2}$. For the BST65/35 $4 \% \quad \mathrm{TiO}_{2}$ random 3D mixing ceramics, $\mathrm{TiO}_{2}$ microspheres were prepared by spray drying (B 290 Buchi $^{\circledast}$ device, Büchi Labortechnik AG, Flawil, Swit zerland) from a suspension of nanocrystalline rutile $\mathrm{TiO}_{2}$ powder $\left(98 \%\right.$ purity, Dupont ${ }^{\circledR}$, Wilmington, DE. The as obtained spherical microsized particles (size about $40 \mu \mathrm{m}$ ) were first consolidated individually at $1400^{\circ} \mathrm{C}$ during $2 \mathrm{~h}$. SPS (SYNTEX, Dr. Sinter 515S, Kanagawa, Japan) was car ried out in vacuum using a uniaxial pressure of $90 \mathrm{MPa}$. The sintering temperatures and the holding time were $1200^{\circ} \mathrm{C}$ and $1300^{\circ} \mathrm{C}$, and $10 \mathrm{~min}$, respectively. A pulse configuration of 12 pulses followed by two periods of zero current was used. Postannealing at $800^{\circ} \mathrm{C}$ during $10 \mathrm{~h}$ under air were per formed to reoxidize the ceramics. Microstructure and chemi cal analysis of the composites were conducted using Scanning Electron Microscope (SEM, JSM 6330A; JEOL, Tokyo, Japan) and Electron Probe Micro Analysis (EPMA, CAMECA SX100, Gennevelliers, France).

\section{Results and Discussion}

\section{(1) Control of Interdiffusion in $\mathrm{BST} / \mathrm{TiO}_{2}$ Bilayers Through SPS Conditions}

An interphase between the BST and $\mathrm{TiO}_{2}$ phases was observed in SPS bilayers. EPMA analysis revealed a preferen tial diffusion of barium into the $\mathrm{TiO}_{2}$ layer leading to the for mation of barium titanate hollandite phase $\mathrm{Ba}_{x} \mathrm{Ti}_{2 x}{ }^{3+}$ $\mathrm{Ti}_{8-2 x}{ }^{4+} \mathrm{O}_{16-\delta}$. This is in good agreement with the higher mobility of $\mathrm{Ba}^{2+}$ cations. ${ }^{12,13}$ The existence of a solid solution with a single phase region corresponding to a barium concen tration in the range $1.143<x<1.333$ was reported in litera ture. ${ }^{14}$ Furthermore, the structure can adopt oxygen deficient stoichiometry (up to $\delta \quad 0.4$ ) according to the temperature and the atmosphere conditions. ${ }^{15}$ In the present work, the low oxygen partial pressure during sintering favors the cre ation of oxygen vacancies and associated $\mathrm{Ti}^{4+}$ reduction into $\mathrm{Ti}^{3+}$ that are preferentially localized within $\mathrm{TiO}_{2}$ layer. This 
is confirmed by the dark color of the $\mathrm{TiO}_{2}$ layer whereas BST layer remains white. The hollandite type interphase obtained is thus assumed to be oxygen deficient with a barium concen tration close to 1.14 according to EPMA analysis. However, a gradient of compositions within the hollandite phase region can be expected depending upon the thickness of interface. Further chemical and TEM analyses are required to accu rately determine the composition. Here, we focused on two specific parameters to understand how the interphase is formed: the sintering temperature and the direction of the current with regard to the order of layers within the stack. The sintering temperature window was selected to enhance the defects mobility and the holding time was maintained short enough to rise the role of the electrical current with respect to thermodynamic equilibria and transport kinetics. At a sintering temperature of $1300^{\circ} \mathrm{C}$, changing the layers sequence versus the direction of the electric current clearly highlighted a modification of the interface thickness: when the $\mathrm{TiO}_{2}$ layer was in contact with the positive electrode, the interphase thickness is $200 \mu \mathrm{m}$ [Fig. 1(a)], whereas the value decreases down to $100 \mu \mathrm{m}$ [Fig. 1(b)] when reversing the $\mathrm{BST} 65 / 35 \mathrm{TiO}_{2}$ stacking. A decrease in the sintering temperature from $1300^{\circ} \mathrm{C}$ to $1200^{\circ} \mathrm{C}$ led to a decrease in interphase thickness whatever the order of the layers within the stacks [Figs. 1(c d)]. Combining a lower sintering tem perature with the current direction effect allows reducing the interphase thickness down to $10 \mu \mathrm{m}$. This result is fully reproducible confirming thus the direct effect of the current flow on the defects mobility through the interface.

\section{(2) Dielectric Properties of Bilayers}

Dielectric measurements were performed on postannealed SPS bilayers. Permittivity values are in the range 40005000 [Fig. 2 (a d)] whatever the interphase thickness. However, an increase in the dielectric losses peak at low temperature is

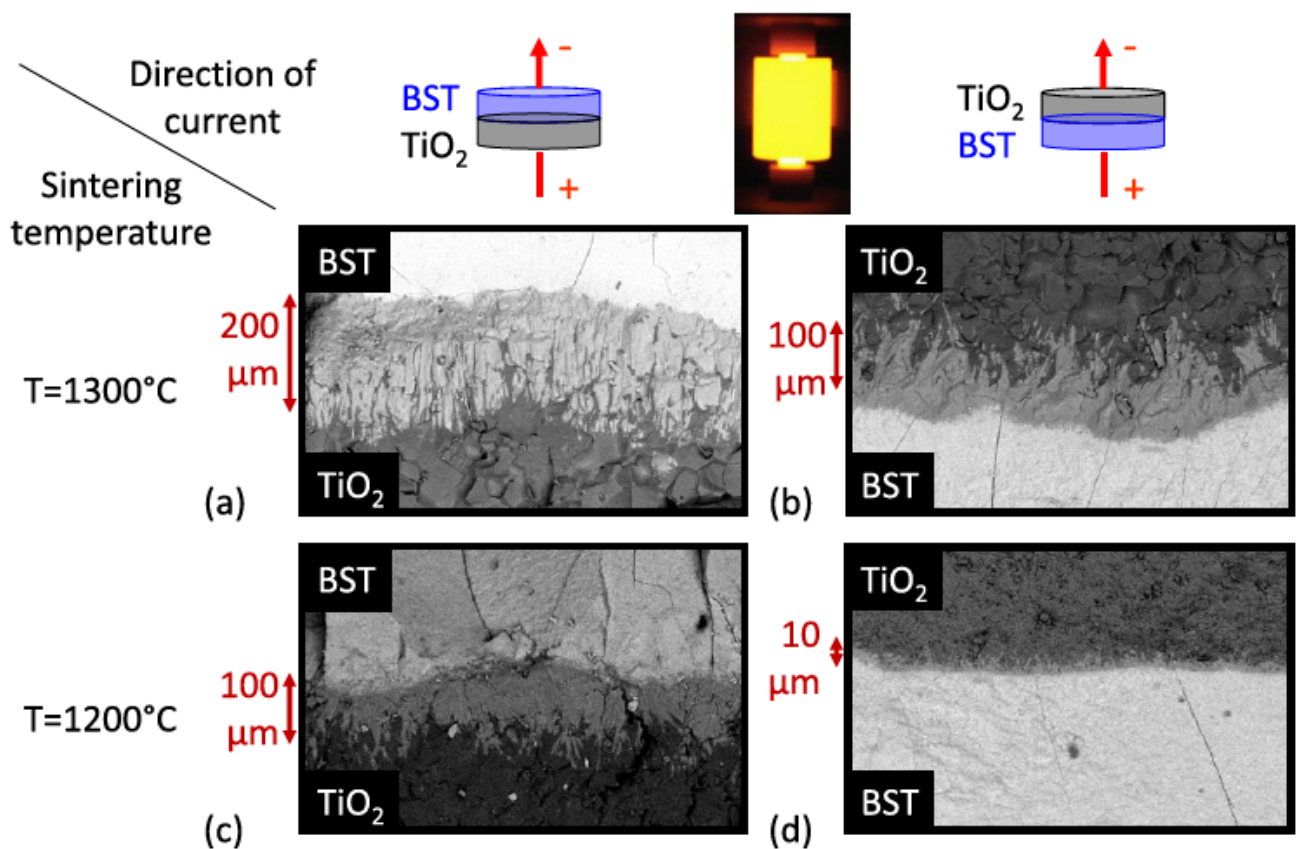

Fig. 1. (a d) SEM micrographs of the fracture surface of $\mathrm{BST} 65 / 35 \mathrm{TiO}_{2}$ bilayers. The thickness of the $\mathrm{Ba}_{1.14(2)} \mathrm{Ti}_{8} \mathrm{O}_{16} \delta$ interphase depends on the sintering temperature and on the electric current direction.
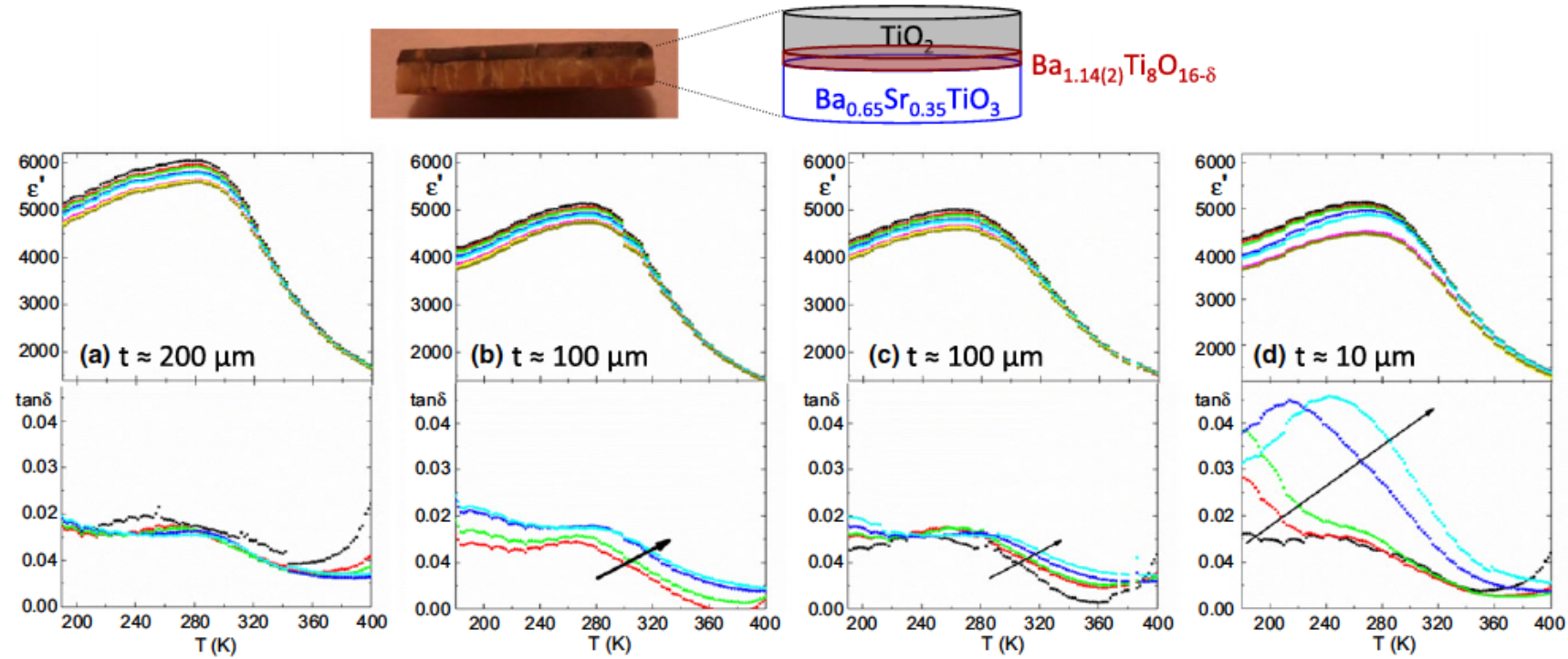

Fig. 2. Picture and schematic representation of the $\mathrm{BST} 65 / 35 \mathrm{TiO}_{2}$ bilayer. Temperature and frequency dependences of the permittivity and losses of bilayers with different interphase thicknesses: (a) $t \approx 200 \mu \mathrm{m}$, (b c) $t \approx 100 \mu \mathrm{m}$ (sintered at $1300^{\circ} \mathrm{C}$ and $1200^{\circ} \mathrm{C}$, respectively), and (d) $t \approx 10 \mu \mathrm{m}$. Black arrow indicates increased frequency from $100 \mathrm{~Hz}$ to $10 \mathrm{kHz}$ 


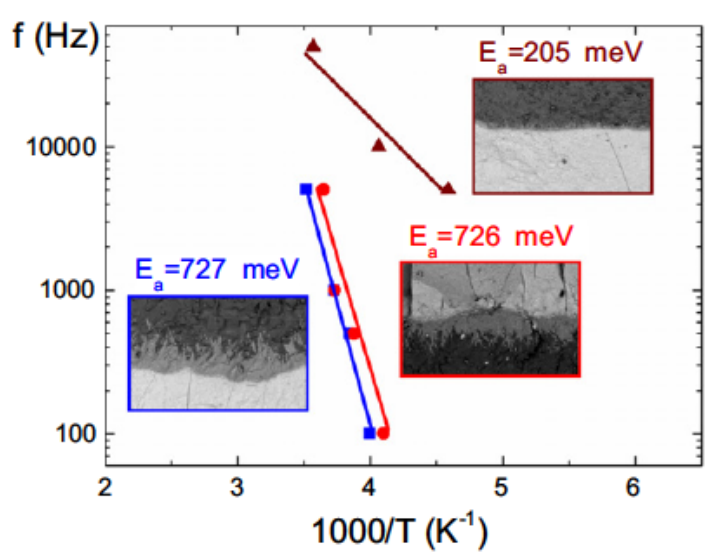

Fig. 3. Arrhenius plot for the $\mathrm{BST} 65 / 35 \mathrm{TiO}_{2}$ bilayers $\left(t_{\text {(interphase })} \approx 100\right.$ and $\left.10 \mu \mathrm{m}\right)$. Activation energies of the dielectric relaxations are reported.

observed for the composite with the $10 \mu \mathrm{m}$ thin interphase [Fig. 2(d)].

Plotting the operating frequency at which the loss peak occurs versus the temperature on an Arrhenius scale (Fig. 3), the activation energy, which is the slope of these lines, can be linked to the thickness of the interphase in the bilayers. The activation energy is large $\left(E_{\mathrm{a}}>600 \mathrm{meV}\right)$ for $t \approx 100 \mu \mathrm{m}$ (whatever the sintering temperature) while it is reduced in thinner interphase ( $E_{\mathrm{a}} 205 \mathrm{meV}$ for $\left.t \approx 10 \mu \mathrm{m}\right)$. Such an effect is quite unexpected since the dielectric activa tion energy should be related to intrinsic parameters and not to interface microstructure. $\mathrm{Ti}^{3+}$ impurity levels linked to oxygen vacancies can be excluded since such defects lead to low activation energies $\left(E_{\mathrm{a}}<100 \mathrm{meV}\right)$ resulting from the vicinity of these levels to the bottom of the conduction band. The changes in activation energies may be due to the compo sition of the interphases. Indeed, for thin interphases the composition, mainly $\mathrm{Ba}^{2+}$ concentration that can vary over more than $10 \mu \mathrm{m}$, never reaches the stable one that may favor the charges mobility (including the ionic one) thus reducing the activation energy. On the other hand, for inter phases much thicker than the zone of composition variation, stable and well compensated interphase is to arise far from the $\mathrm{BST} \mathrm{TiO}_{2}$ interface. As a result, conductivity barrier maybe built in such interphases and the activation energy is larger. Beyond the qualitative link between the interphase thickness and the activation energy, more investigations are needed to clarify this link.

\section{(3) Dielectric Properties of Multilayer and 3D Composite}

The number of interfaces was increased in multilayers and 3D composite (Fig. 4). Whatever the architectures, $\mathrm{TiO}_{2}$ is prefer entially reduced and an interphase is formed with a composi tion similar to the one detected in bilayers. A dielectric relaxation is measured in both cases [Fig. 4(a)]. In the 3D composite, giant permittivity $\left(\varepsilon_{\max }^{\prime}(10 \mathrm{kHz}) \quad 53400\right)$ and high dielectric losses $(\tan \delta>1)$ are obtained even after postan nealing [Fig. 4(b)]. The reoxidation of the $\mathrm{TiO}_{2}$ inclusions can be tuned by successive calcinations in air as shown by the strong decrease in both the dielectric permittivity and losses.

\section{Conclusion}

BST65/35 $\mathrm{TiO}_{2}$ composites with $2 \mathrm{D}$ and $3 \mathrm{D}$ architectures sintered by SPS led to the formation of $\mathrm{Ba}_{1.14(2)} \mathrm{Ti}_{8} \mathrm{O}_{16-\delta}$ interphase. This interphase, originating in the $\mathrm{TiO}_{2}$ phase, is
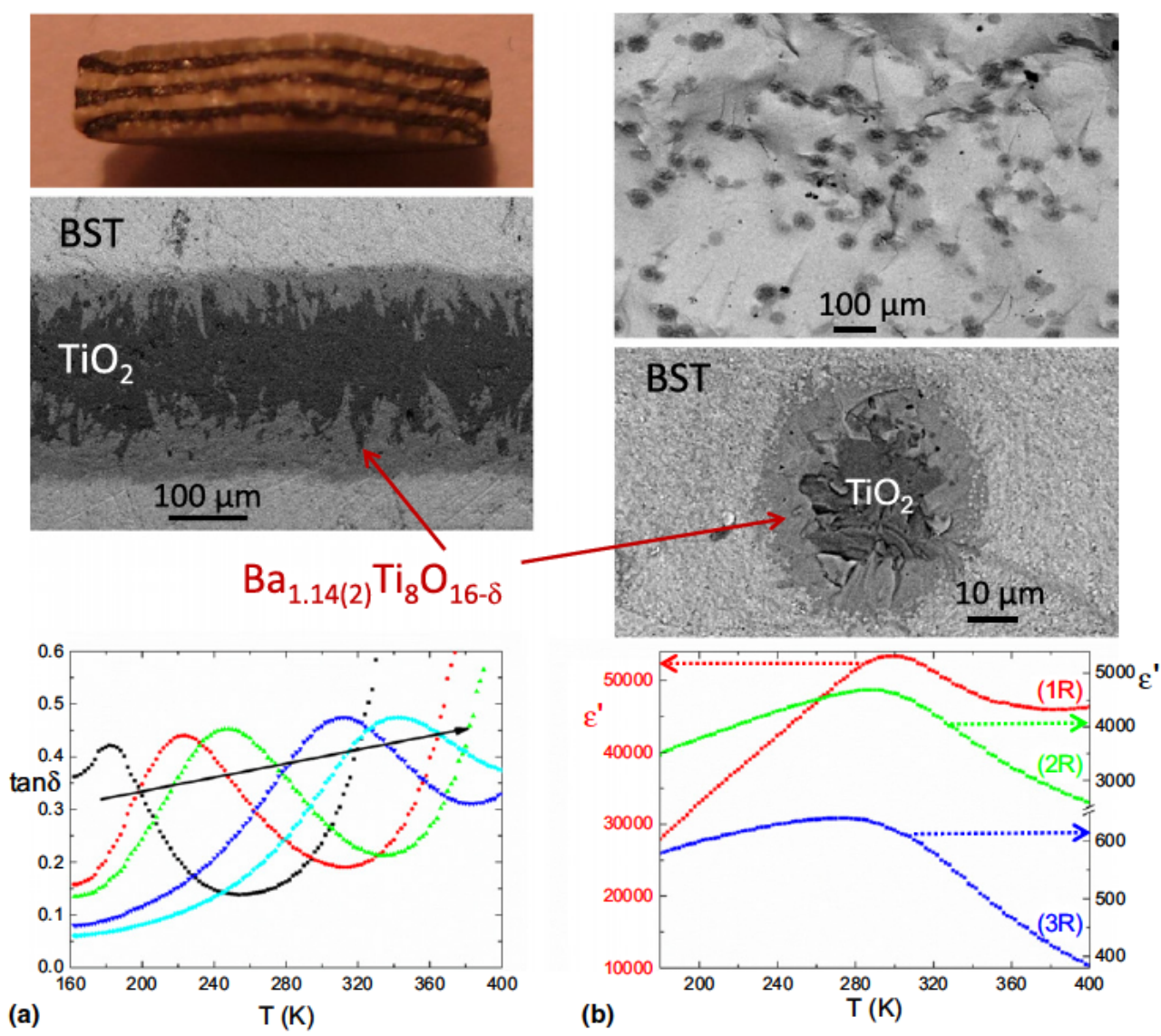

Fig. 4. SEM micrographs of the fracture surfaces of (a) the multilayer and (b) the 3D ceramics. (a) Dielectric relaxation is represented by a black arrow with increasing frequency from $100 \mathrm{~Hz}$ to $10 \mathrm{kHz}$. (b) Temperature dependences of the dielectric permittivity at $10 \mathrm{kHz}$ after three successive reoxidation steps $(1 \mathrm{R}, 2 \mathrm{R}$ and $3 \mathrm{R})$. 
oxygen depleted as compared to $\mathrm{TiO}_{2}$, and $\mathrm{Ba}^{2+}$ ions diffuse from BST to compensate the oxygen deficiency. The inter phase growth rate can be tuned by the sintering temperature and the direction of the electric current during SPS. We sug gest that such interphase control, which was never observed in dielectric multilayers, can be extended to other interphases between oxides of different reduction ability. We also found that the activation energy of a dielectric relaxation that appears close to room temperature depends strongly on the interphase thickness. Such a tuning is rather seldom because dielectric relaxations that originate from charged impurities mostly rely on their induced energy level within the band gap, but not on the extent of the interphases. Increasing the number of interfaces in 3D composite may result in giant permittivity and the permittivity can be tuned through reoxi dation cycles. Further work is in progress to understand such interface driven dielectric properties when increasing the den sity of interfaces while remaining below the percolation threshold.

\section{Acknowledgments}

This work was partly funded by the ANR project ARCHIFUN (ANR-12BS08-009). A. Kassas was supported by the LabEx AMADEus (ANR-10LABX-42) in the framework of IdEx Bordeaux (ANR-10-IDEX-03-02) i.e., the Investissements d'Avenir programme of the French government managed by the Agence Nationale de la Recherche.

\section{References}

${ }^{1}$ S. Guillemet-Fritsch, Z. Valdez-Nava, C. Tenailleau, T. Lebey, B. Durand, and J.-Y. Chane-Ching, "Colossal Permittivity in Ultrafine Grain Size $\mathrm{BaTiO}_{3}$ and $\mathrm{Ba}_{0}{ }_{95} \mathrm{La}_{0}{ }_{05} \mathrm{TiO}_{3}$ x Materials," Adv. Mater., 20, 5515 (2008).
${ }^{2} \mathrm{H}$. Han, et al., "Origin of Colossal Permittivity in $\mathrm{BaTiO}_{3}$ via Broadband Dielectric Spectroscopy,” J. Appl. Phys., 113, 024102, 8pp (2013).

${ }^{3}$ A. Artemenko, et al., "Linking Hopping Conductivity to Giant Dielectric Permittivity in Oxides", Appl. Phys. Lett, 97, 132901, 8pp (2010).

${ }^{4}$ J. Li, F. Li, C. Li, G. Yang, Z. Xu, and S. Zhang, "Evidences of Grain Boundary Capacitance Effect on the Colossal Dielectric Permittivity in $(\mathrm{Nb}+$ In) co-Doped $\mathrm{TiO}_{2}$ Ceramics," Sci. Rep., 5, 8295, 8pp (2015).

${ }^{5}$ J. Gurt Santanach, et al., "Influence of Pulse Current Spark Plasma Sintering Evidenced on Reactive Alumina-Hematite Powders," J. Eur. Ceram. Soc., 31, 224754 (2011).

${ }^{6}$ J. E. Garay, U. Anselmi-Tamburini, and Z. A. Munir, "Enhanced Growth of Intermetallic Phases in the Ni-Ti System by Current Effects," Acta Mater., 51, 448795 (2003).

${ }_{7}^{7}$. R. Friedman, J. E. Garay, U. Anselmi-Tamburini, and Z. A. Munir, "Modified Interfacial Reactions in Ag-Zn Multilayers Under the Influence of High DC Currents," Intermetallics, 12, 58997 (2004).

${ }^{8}$ Y. Zhou. Q. Wang, D. L. Sun, and X. L. Han, "Co-Effect of Heat and Direct Current on Growth of Intermetallic Layers at the Interface of Ti-Ni Diffusion Couples," J. Alloy. Compd., 509, 12015 (2011).

${ }^{9}$ U. Anselmi-Tamburini, J. E. Garay, and Z. A. Munir, "Fundamental Investigations on the Spark Plasma Sintering/Synthesis Process III. Current Effect on Reactivity," Mater. Sci. Eng., A, 407, 2430 (2005).

${ }^{10}$ T. Kondo, M. Yasuhara, T. Kuramoto, Y. Kodera, M. Ohyanagi, and Z. A. Munir, "Effect of Pulsed DC Current on Atomic Diffusion of Nb-C Diffusion Couple," J. Mater. Sci., 43, 64005 (2008).

${ }^{11} Z$. Trzaska and J.-P. Monchoux, "Electromigration Experiments by Spark Plasma Sintering in the Silver-Zinc System," J. Alloy. Compd., 635, 1429 (2015).

${ }^{12}$ M. T Buscaglia, M. Viviani, Z. Ahao, V. Buscaglia, and P. Nanni, "Synthesis of $\mathrm{BaTiO}_{3}$ Core-Shell Particles and Fabrication of Dielectric Ceramics With Local Graded Structure," Chem. Mat, 18, 400210 (2006).

${ }^{13}$ U.-C. Chung, et al., "Interface Investigation in Nanostructured $\mathrm{BaTiO}_{3} /$ Silica Composite Ceramics," J. Am. Ceram. Soc., 93, 86574 (2010).

${ }^{14}$ D. S. Filimonov, Z.-K. Liu, and C. A. Randall, "Phase Relations in the

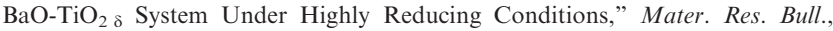
38, 54553 (2003).

${ }^{15}$ D. S. Filimonov, Z.-K. Liu, and C. A. Randall, "An Oxygen Nonstoichiometry Study of Barium Polytitanates With Hollandite Structure," Mater. Res. Bull., 37, 237382 (2002). 